\title{
Antibiogram and recent incidence of multi-drug resistant carbapenemase producing Escherichia coli isolated from paediatric patients
}

\author{
Sumbal Nosheen ${ }^{1}$, Nadeem Irfan Bukhari², \\ Hasan $\mathrm{Ejaz}^{3}$, Nasir Abbas ${ }^{4}$
}

\begin{abstract}
Objective: To gauge the recent breadth of MDR E. coli along with antibiogram of carbapenemase producing (CP) E. coli among children from an institute which receives patients from all over Punjab.

Methods: The bacterial strains of $E$. coli isolated from various specimens of patients were collected from April 2017 to August 2018 and processed using standard biochemical tests and API 20E system (bioMerieux). Phenotypic screening for CP E. coli was done by the modified Hodge test, whereas antibiotic susceptibility testing was done with Kirby-Bauer disc diffusion technique.

Results: Total of 6,468 bacterial strains were isolated, out of which 1,552 (24\%) were E. coli. Carbapenem resistance was observed in $245(16 \%)$ strains, amongst which $113(46 \%)$ were confirmed to be CP. E. coli isolated from males were higher as compared to females $(\mathrm{p}<0.05)$. Majority of the organisms were isolated from blood (37.2\%) samples. The hospital discharged about $65 \%$ of patients, while $23 \%$ left against medical advice. Overall MDR amongst E. coli was $93.26 \%$. Colistin sulphate $(15.9 \%)$ and nitrofurantoin $(16.8 \%)$ showed the most efficacy followed by amikacin (15\%) and fosfomycin (10.6\%).

Conclusion: The isolation of high number of MDR E. coli amongst the paediatric patients is worrisome, which could serve as a potential source of horizontal genes transfer to other genera.
\end{abstract}

KEYWORDS: Antibiotic resistance, Multi-drug resistance, Escherichia coli, Carbapenemase producers.

How to cite this:

doi: https://doi.org/10.12669/pjms.36.2.928

Nosheen S, Bukhari NI, Ejaz H, Abbas N. Antibiogram and recent incidence of multi-drug resistant carbapenemase producing Escherichia coli isolated from paediatric patients. Pak J Med Sci. 2020;36(2):246-250. doi: https://doi.org/10.12669/pjms.36.2.928

This is an Open Access article distributed under the terms of the Creative Commons Attribution License (http://creativecommons.org/licenses/by/3.0), which permits unrestricted use, distribution, and reproduction in any medium, provided the original work is properly cited.

1. Dr. Sumbal Nosheen, M.Phil.

2. $\quad$ Dr. Nadeem Irfan Bukhari, Ph.D.

3. Dr. Hasan Ejaz, Ph.D.

Department of Clinical Laboratory Sciences,

College of Applied Medical Sciences,

Jouf University, Sakaka, Saudi Arabia.

4. Dr. Nasir Abbas, Ph.D.

1,2,4: Punjab University College of Pharmacy (PUCP), University of the Punjab,

Lahore, Pakistan.

Correspondence:

Prof. Dr. Nadeem Irfan Bukhari, Punjab University College of Pharmacy, University of the Punjab, Allama Iqbal Campus, Lahore-54000, Pakistan.

E-mail: nadeem_irfan@hotmail.com

* Received for Publication:

April 20, 2019

* Revision Received:

* Revision Accepted:

\section{INTRODUCTION}

Multiple-drug resistance (MDR) is developed in microorganisms against two or more antibiotics concomitantly due to either production of bacterial enzymes against them, modification in bacterial penicillin-binding proteins, their extrusion by efflux pump or mutations in transferable genes to other bacteria through mobile genetic elements. ${ }^{1}$

Most Gram-negative microbes like E. coli are resistant to various antibiotics classes including penicillins, cephalosporin, macrolides and aminoglycosides. Such MDR infections are difficult to treat in compromised paediatric patients which may lead to severe consequences 
like delayed treatment, prolonged hospitalization, complications, repeated hospital visits and even deaths if could not be managed. ${ }^{2}$

Carbapenems have a strong affinity for the penicillin-binding proteins present on bacterial membrane and are stable against extendedspectrum beta-lactamase and therefore shows high permeability in the bacterial outer membrane. ${ }^{3}$ As the bacteria producing carbapenemases have begun to emerge, MDR infections are becoming more formidable challenge. ${ }^{4}$

Carbapenem resistant $E$. coli has now considered among most important nosocomial pathogens that can cause a variety of infections including urinary tract infections (UTI), intestinal and extraintestinal ailments like diarrhoea and neonatal meningitis. ${ }^{5}$ The carbapenems are regarded as an empirical treatment choice for all severe infections due to AmpC and extended-spectrum $\beta$-lactamase producing E. coli. An increase in the prevalence of the above diseases has been documented in recent years with wide variations in incidence among different regions of the world. ${ }^{6}$

In the US, E. coli induced UTIs among paediatric patients to result in approximately eight million health practitioner visits per year. ${ }^{7}$ Therapeutic options for the treatment of such bacteria are now limited, and the delays in the detection of carbapenemase production by bacteria mostly leads to the treatment failure, prolonged hospital stay, increased morbidity, mortality and healthcare cost. $^{8}$ Thus, evaluation of the antimicrobial resistance pattern of carbapenemase producing $E$. coli in local paediatric patients has been warranted. We aimed the study to evaluate the incidence of multi-drug resistant carbapenemase producing $E$. coli in paediatric patients attending a tertiary care hospital of Lahore, Pakistan. Likewise, the patient's statistic information is a valuable supplement to sensitivity data in distinguishing patient groups at high danger of infection.

\section{METHODS}

This prospective study was carried out on E. coli from all of the pathological samples received at the Department of Microbiology from admitted and ambulatory patients attending hospital, received at the Department of Microbiology, The Children's Hospital Lahore from April 2017 to August 2018 after approval from the institutional ethical committee. We processed a total number of 52,163 specimens for 17 months for the isolation of carbapenemase producing E. coli.
The specimens of blood, ear swab tip, central venous pressure (CVP) tip, peritoneal dialysis (PD) catheter, pus, urine, tracheal secretion, cerebrospinal fluid (CSF), endotracheal tube (ETT), and wound swab were cultured on the Blood and MacConkey agar plates. After incubation, the strains were identified morphologically and by using Gram's stain, various biochemical tests and API 20 E. ${ }^{9}$ Phenotyping for carbapenemase detection in E. coli in the specimen was done by the modified Hodge test (MHT) and combined disc test (CDT). The appearance of clover leaf-like indentation showed MHT positive carbapenemase producing E. coli. ${ }^{10}$ The non-repetitive isolates, resistant to any of the carbapenem drug were included from the study. The demographic data of the enrolled cases was obtained from the patient files.

The data were analyzed by using SPSS version 23.0. Gender was compared for output with different wards, specimens and outcomes like mortality and discharge by using the Chi-square test. A p-value $<0.05$ was considered significant. Friedman's test was employed to compare the difference in the effect of antibiotics on the strains of carbapenemase producing E. coli.

\section{RESULTS}

We isolated a total of 6,468 (12.3\%) different bacterial isolates out of which 1,552 (24\%) were identified as E. coli. Resistance against carbapenems was observed in 245/1552 (16\%) isolates, amongst which 113/245 (46\%) were found to be CP by MHT and CDT.

The highest number of isolated bacterial strains was $42(37.2 \%)$ from urine and $40(35.4 \%)$ from the blood. There were $22(19.5 \%)$ samples collected from the neonatal unit, followed by 15 (13.3\%) from oncology and $14(12.4 \%)$ from ICUs. A total of $56(49.6 \%)$ CP strains were recovered from the females while $57(50.4 \%)$ from male patients. The overall outcome showed that $73(65 \%)$ patients were discharged after successful treatment while $23(20 \%)$ patients left against the medical advice (LAMA). There were $17(15 \%)$ cases of mortality. No statistical association $(p>0.05)$ was found between the gender with the outcome, specimen and wards (Table-I).

Antibiogram was determined by the Kirby Bauer disc diffusion method. The antibiotics used were those as given in Table-II. The diameter of each zone of inhibition was identified and interpreted as sensitive, intermediate or resistant as described in CLSI guidelines. ${ }^{10}$ E-test was also used to 
Table-I: Demographic data of patients infected with CP E. coli infections $(n=113)$.

\begin{tabular}{|c|c|c|}
\hline Specimen & Frequency $(n)$ & Percentage (\%) \\
\hline Blood & 42 & $37.20 \%$ \\
\hline Ear Swab Tip & 3 & $2.70 \%$ \\
\hline CVP Tip & 4 & $3.50 \%$ \\
\hline PD Catheter & 4 & $3.50 \%$ \\
\hline Pus & 6 & $5.30 \%$ \\
\hline Urine & 40 & $35.40 \%$ \\
\hline Tracheal secretion & 2 & $1.80 \%$ \\
\hline CSF & 9 & $8 \%$ \\
\hline ETT & 1 & $0.90 \%$ \\
\hline Wound Swab & 2 & $1.80 \%$ \\
\hline Wards & requency $(n)$ & Percentage (\%) \\
\hline Neonatal Unit & 22.0 & $19.5 \%$ \\
\hline Development Ward & 2.0 & $1.8 \%$ \\
\hline Surgery Ward & 4.0 & $3.5 \%$ \\
\hline All Intensive Care Units (ICUs) & Js) 14.0 & $12.4 \%$ \\
\hline Medical Emergency & 2.0 & $1.8 \%$ \\
\hline Haematology/Oncology Unit & 15.0 & $13.3 \%$ \\
\hline Cardiology Ward & 1.0 & $0.9 \%$ \\
\hline Outdoor Patients (OPD) & 7.0 & $6.2 \%$ \\
\hline Urology Ward & 3.0 & $2.7 \%$ \\
\hline General Medical Unit-I & 3.0 & $2.7 \%$ \\
\hline General Medical Unit-II & 11.0 & $9.7 \%$ \\
\hline General Medical Unit-III & 4.0 & $3.5 \%$ \\
\hline General Medical Unit-IV & 3.0 & $2.7 \%$ \\
\hline Nephrology Ward & 15.0 & $13.3 \%$ \\
\hline Gastroenterology Ward & 3.0 & $2.7 \%$ \\
\hline Neurology ward & 1.0 & $0.9 \%$ \\
\hline Neuro-Surgery ward & 3.0 & $2.7 \%$ \\
\hline Gender & Frequency $(n)$ & Percentage (\%) \\
\hline Female & 56 & $49.6 \%$ \\
\hline Male & 57 & $50.4 \%$ \\
\hline Outcome & Frequency $(n)$ & Percentage (\%) \\
\hline Discharge & 73 & $65 \%$ \\
\hline Death & 17 & $15 \%$ \\
\hline $\begin{array}{l}\text { LAMA (left against } \\
\text { medical advice) }\end{array}$ & 23 & $20 \%$ \\
\hline
\end{tabular}

measure the minimum inhibitory concentration of anti-microbial susceptibility of $E$. coli against colistin. The intersection point of the drop-shaped inhibition zone and the graded E-strip showing the inhibitory concentration of colistin was interpreted according to CLSI. All strains showing lower susceptibility to carbapenems like imipenem and meropenem were screened to be $\mathrm{CP}$ by using MHT and CDT. ${ }^{10}$

In antimicrobial susceptibility testing, colistin sulphate $(15.9 \%)$ and nitrofurantoin $(16.8 \%)$ were
Table-II: Antibiogram of carbapenemase producing E. coli $(\mathrm{n}=113)$.

\begin{tabular}{|c|c|c|c|c|c|c|}
\hline \multirow[t]{2}{*}{ Antibiotics* } & \multicolumn{2}{|c|}{ Resistant } & \multicolumn{2}{|c|}{ Sensitive } & \multicolumn{2}{|c|}{ Intermediate } \\
\hline & No. & $\%$ & No. & $\%$ & No. & $\%$ \\
\hline \multicolumn{7}{|l|}{ Cephalosporin } \\
\hline Cefoxitin & 95 & 84.1 & 12 & 10.6 & 6 & 5.3 \\
\hline Cefuroxime & 109 & 96.5 & 4 & 3.5 & 0 & 0.0 \\
\hline Cefixime & 110 & 97.3 & 3 & 2.7 & 0 & 0.0 \\
\hline Ceftazidime & 113 & 100.0 & 0 & 0.0 & 0 & 0.0 \\
\hline Ceftriaxone & 111 & 98.2 & 2 & 1.8 & 0 & 0.0 \\
\hline Cefotaxime & 113 & 100.0 & 0 & 0.0 & 0 & 0.0 \\
\hline Cefepime & 104 & 92.0 & 5 & 4.4 & 4 & 3.5 \\
\hline \multicolumn{7}{|l|}{ Aminoglycosides } \\
\hline Amikacin & 96 & 85.0 & 17 & 15.0 & 0 & 0.0 \\
\hline Gentamycin & 108 & 95.6 & 5 & 4.4 & 0 & 0.0 \\
\hline Tobramycin & 110 & 97.3 & 3 & 2.7 & 0 & 0.0 \\
\hline \multicolumn{7}{|c|}{ Polypeptide Polymyxin Antibiotics } \\
\hline Colistin & 89 & 78.8 & 18 & 15.9 & 6 & 5.3 \\
\hline \multicolumn{7}{|l|}{ Quinolones } \\
\hline Nalidixic acid & 108 & 95.6 & 5 & 4.4 & 0 & 0.0 \\
\hline \multicolumn{7}{|c|}{ Fluoroquinolones } \\
\hline Levofloxacin & 108 & 95.6 & 5 & 4.4 & 0 & 0.0 \\
\hline Moxifloxacin & 112 & 99.1 & 0 & 0.0 & 1 & 0.9 \\
\hline Ciprofloxacin & 106 & 93.8 & 5 & 4.4 & 2 & 1.8 \\
\hline Norfloxacin & 102 & 90.3 & 11 & 9.7 & 0 & 0.0 \\
\hline \multicolumn{7}{|l|}{ Monobactams } \\
\hline Aztreonam & 107 & 94.7 & 6 & 5.3 & 0 & 0.0 \\
\hline \multicolumn{7}{|l|}{ Nitrofurans } \\
\hline Nitrofurantoin & 92 & 81.4 & 19 & 16.8 & 2 & 1.8 \\
\hline \multicolumn{7}{|l|}{ Carbapenems } \\
\hline Imipenem & 105 & 92.9 & 4 & 3.5 & 4 & 3.5 \\
\hline Meropenem & 103 & 91.2 & 5 & 4.4 & 5 & 4.4 \\
\hline \multicolumn{7}{|l|}{ Others } \\
\hline Fosfomycin & 101 & 89.4 & 12 & 10.6 & 0 & 0.0 \\
\hline Pipemidic acid & 112 & 99.1 & 1 & 0.9 & 0 & 0.0 \\
\hline \multicolumn{7}{|c|}{ Combination Antibiotics } \\
\hline Co-amoxiclav & 109 & 96.5 & 4 & 3.5 & 0 & 0.0 \\
\hline $\begin{array}{l}\text { Piperacillin- } \\
\text { tazobactam }\end{array}$ & 105 & 92.9 & 2 & 1.8 & 6 & 5.3 \\
\hline Co-trimoxazole & 110 & 97.3 & 3 & 2.7 & 0 & 0.0 \\
\hline $\begin{array}{l}\text { Cefoperazone- } \\
\text { sulbactam }\end{array}$ & 102 & 90.3 & 4 & 3.5 & 7 & 6.2 \\
\hline
\end{tabular}

${ }^{*} p<0.05$ using Friedman test used to see the difference in the effects of antibiotics.

found to be the most effective antibiotic in vitro followed by amikacin (15\%) and fosfomycin (10.6\%). The overall MDR among E. coli strains was found to be $93.26 \%$. The bacterial isolates were found to be $100 \%$ resistant to cefotaxime and ceftazidime. Lower susceptibility rates were seen for cefoperazonesulbactam (3.5\%) and piperacillin-tazobactam $(1.8 \%)$. The $\mathrm{p}$-value $<0.05$ indicated that there was a difference in the effects of antibiotics (Table-II). 


\section{DISCUSSION}

In this study, we included the patients received at a prominent paediatric hospital at Lahore, which is serving such patient population from all over the Punjab province and reported $16 \%$ CP E. coli. A study at Indian hospital identified 22 E. coli isolates, all of which showed complete resistance against carbapenem antibiotics. ${ }^{11}$ In another study in Los Angeles, USA, eleven E. coli strains were identified out of which $5(45.4 \%)$ were CP. ${ }^{12}$ A study conducted at Karachi hospital reported the maximum cases of $\mathrm{CP}$ from urine samples $(40 \%) \cdot{ }^{13}$ However, in our study, the maximum of CP E. coli were isolated from blood samples $(37.2 \%)$.

In our study, only $6.2 \%$ CP E. coli strains were isolated from outpatients while $93.8 \%$ from hospitalized patients which is in contrast to an Iranian study, where a lower frequency of E. coli $(33 \%)$ was isolated from inpatients than from outpatients $(66 \%){ }^{14}$ A study including seven US hospitals showed that $51 \%$ of MDR CP E. coli were isolated from ICUs followed by medical ward $(38 \%)$ and surgery unit $(20 \%){ }^{7}$ These remarkably high prevalence values are unprecedented with the frequency of our study in which only $12.4 \%$ cases were from ICUs, $18.6 \%$ from general medical and surgery ward. The reason for the higher risk of nosocomial infections in ICUs patients may be due to the critical condition and suppressed immunity of the patients needing intensive care.

The frequency of CP E. coli strains was higher in males $57(50.4 \%)$ than females $56(49.6 \%)$ in this study. Contrarily, E. coli infection was found to be higher in females (71\%) than in male patients $(55 \%)$ in another study. ${ }^{15}$ The reason for such a contradiction with our result may be due to the fact that the parents in the developing countries bring male children more to the hospital in comparison to the female.

In a study conducted at St. Louis teaching hospital, the mortality rate of patients with MDR E. coli infection was $61.9 \%$ which is quite high in comparison to our study $(15 \%) .{ }^{16}$ Mortality related to such infections can be predetermined to be present with patients acquiring nosocomial infections during the hospital stay or due to interventions like surgeries.

The present study showed an alarming increased rate in MDR in E. coli $(93.26 \%)$ as compared to other study carried out in Sudan $(57 \%) .{ }^{17}$ A US study reported $92 \%$ E. coli to be sensitive to colistin, which is higher than our study $(15.9 \%) .{ }^{18}$ The current study expressed that most of E. coli were concurrently MDR against different antibiotic classes like cephalosporins, aminoglycosides, fluoroquinolones and carbapenems. Similar reports by others showed higher resistance to these antibiotics. ${ }^{14}$ A possible reason for the high co-resistance found in such strains could be the modification of bacterial genes; hence producing enzymes like metallobeta-lactamases, resulting in increased resistance. A study from India also reported high resistance to CP strains to aminoglycosides, beta-lactams, sulphonamides and fluoroquinolones. ${ }^{11}$ Various factors like polypharmacy, lesser trends of using targeted antibiotics and not promoting bacterial identification tests contribute towards higher resistance patterns of MDR E. coli.

Sahm et al. reported $7.1 \%$ MDR E. coli in $2000 .{ }^{19}$ A very high incidence of metallo-betalactamase $(97.8 \%)$ producing bacteria resistant to carbapenems, aminoglycosides, cephalosporin and fluoroquinolones have been reported in paediatric patients. ${ }^{20}$ The relevance of genetic background and the MDR bacteria with a high level of resistance to carbapenems, co-amoxiclav, ampicillin, aztreonam and cephalosporins have been reported amongst the paediatric patients of Pakistan. ${ }^{21}$ Pharmacists can play an integral role in depressing the rapid spread of resistance in pathogens among paediatric patients by involving themselves at clinical levels and promoting rational use of drugs, decreasing the use of un-targeted potent antibiotics as empirical therapy as well as polypharmacy and facilitating the formulation of future antibiotic policies. The study was conducted in the largest tertiary care hospital of Punjab; nevertheless, it was not possible to obtain data on regional and locality basis, a limitation of this study.

\section{CONCLUSION}

This study demonstrated high number of CP producing E. coli from clinical samples of admitted and outpatients from a tertiary care paediatric hospital. The pathogens were combatively less resistant to colistin and amikacin, but some other resistance mechanism could lead to their reduced sensitivity. This high rate of resistance could be a direct result of increased trends towards the use of untargeted potent antibiotics as well as that of 
antibiotic polypharmacy in hospitals as empirical therapy. The understanding of mechanisms of horizontal transfer of genes can be helpful in the development of new policies to fight this health issue of MDR infections.

Acknowledgements: The authors acknowledge the support provided by the Punjab University College of Pharmacy, University of The Punjab, Lahore and The Children's Hospital, Lahore, Pakistan.

Conflict of Interest: None.

Grant Support \& Financial Disclosures: None.

\section{REFERENCES}

1. Hollis A, Ahmed Z. Preserving antibiotics, rationally. N Engl J Med. 2013;369(26):2474-2476. doi: 10.1056/NEJMp1311479

2. Lim K-T, Yasin R, Yeo C-C, Puthucheary S, Thong K-L. Characterization of multidrug resistant ESBL-producing Escherichia coli isolates from hospitals in Malaysia. BioMed Res Int. 2009;2009 Article ID 165637. doi: 10.1155/2009/165637

3. Nordmann P, Gniadkowski M, Giske C, Poirel L, Woodford $\mathrm{N}$, Miriagou $\mathrm{V}$, et al. Identification and screening of carbapenemase producing Enterobacteriaceae. Clin Microbiol Infect. 2012;18(5):432-438. doi: 10.1111/j.14690691.2012.03815.x

4. Girlich D, Poirel L, Nordmann P. Value of the modified Hodge test for detection of emerging carbapenemases in Enterobacteriaceae. J Clin Microbiol. 2011;50(2):447-479. doi: 10.1128/JCM.05247-11

5. Bergeron CR, Prussing C, Boerlin P, Daignault D, Dutil L, Reid-Smith RJ, et al. Chicken as reservoir for extraintestinal pathogenic Escherichia coli in humans, Canada. Emerg Infect Dis. 2012;18(3):415-421. doi: 10.3201/eid1803.111099

6. Rolain J, Parola P, Cornaglia G. New Delhi metallo beta lactamase (NDM-1): Towards a new pandemia? Clin Microbiol Infect. 2010;16(12):1699-1701. doi: 10.1111/j.14690691.2010.03385.x

7. Wisplinghoff $H$, Bischoff $\mathrm{T}$, Tallent SM, Seifert H, Wenzel $\mathrm{RP}$, Edmond MB. Nosocomial bloodstream infections in US hospitals: Analysis of 24,179 cases from a prospective nationwide surveillance study. Clin Infec Dis. 2004;39(3):309317. doi: $10.1086 / 421946$

8. Mehrgan H, Rahbar M, Arab-Halvaii Z. High prevalence of extended-spectrum beta-lactamase-producing Klebsiella pneumoniae in a tertiary care hospital in Tehran, Iran. J Infect Dev Ctries. 2009;4(03):132-138. doi: 10.3855/jidc.488

9. Cheesbrough M. District Laboratory Practice in Tropical Countries: Cambridge University Press; 2006.

10. Clinical and Laboratory Standards Institute (CLSI). Performance Standards for Antimicrobial Susceptibility Testing. 27th ed. Wayne. 2017; M100.

11. Muir A, Weinbren M. New Delhi metallo- $\beta$-lactamase: A cautionary tale. J Hosp Infect. 2010;75(3):239-240. doi 10.1016/j.jhin.2010.02.005

12. Pannaraj PS, Bard JD, Cerini C, Weissman SJ. Paediatric carbapenem-resistant Enterobacteriaceae in Los Angeles, California, a high-prevalence region in the United States. Pediatr Infect Dis J. 2015;34(1):11-16. doi: 10.1097/ INF.0000000000000471
13. Khan FZ, Nawaz T, Mirani ZA, Khan S, Raza Y, Kazmi SU. Study of class 1 integrons in multidrug-resistant uropathogenic Escherichia coli isolated from different hospitals in Karachi. Iran J Med Sci. 2018;21(10):1079-1082. doi: 10.22038/IJBMS.2018.28807.6966

14. Fazeli H, MoghimS,Zare D. Antimicrobial Resistance Pattern and Spectrum of Multiple-drug-resistant Enterobacteriaceae in Iranian Hospitalized Patients with Cancer. Adv Biomed Res. 2018;7:69. doi: 10.4103/abr.abr_164_17.

15. Magliano E, Grazioli V, Deflorio L, Leuci AI, Mattina R, Romano P, et al. Gender and age-dependent etiology of community-acquired urinary tract infections. Sci World J. 2012;349597. doi: $10.1100 / 2012 / 349597$

16. Ibrahim EH, Sherman G, Ward S, Fraser VJ, Kollef MH. The influence of inadequate antimicrobial treatment of bloodstream infections on patient outcomes in the ICU setting. Chest. 2000;118(1):146-155. doi: 10.1378/ chest.118.1.146

17. Ibrahim ME, Bilal NE, Hamid ME. Increased multi-drug resistant Escherichia coli from hospitals in Khartoum state, Sudan. Afr J Health Sci. 2012;12(3):368-375. doi: 10.4314/ ahs.v12i3.19.

18. Deshpande LM, Jones RN, Fritsche TR, Sader HS. Occurrence and characterization of carbapenemase-producing Enterobacteriaceae: Report from the SENTRY Antimicrobial Surveillance Program (2000-2004). Microb Drug Resist. 2006;12(4):223-230. doi: 10.1089/mdr.2006.12.223.

19. Sahm DF, Thornsberry C, Mayfield DC, Jones ME, Karlowsky JA. Multidrug-Resistant Urinary Tract Isolates of Escherichia coli: Prevalence and Patient Demographics in the United States in 2000. Antimicrob. Agents Chemother. 2001;45(5):1402-1406. doi: 10.1128/AAC.45.5.1402-1406.2001

20. Javed H, Ejaz H, Zafar A, Rathore AW, ul Haq I. Metallobeta-lactamase producing Escherichia coli and Klebsiella pneumoniae: A rising threat for hospitalized children. J Pak Med Assoc. 2016;66(9):1068-1072.

21. Heinz E, Ejaz H, Scott JB, Wang N, Gujaran S, Pickard D, et al. Resistance mechanisms and population structure of highly drug resistant Klebsiella in Pakistan during the introduction of the carbapenemase NDM-1. Sci Rep. 2019;20;9(1):2392. doi: 10.1038/s41598-019-38943-7

\section{Authors Contribution:}

SN: Translated idea into experimental, designed the study and written the manuscript, is responsible for integrity of research.

HE: Jointly conceived idea and supervised the work with NIB, contributed in the specimen collection and editing of the manuscript.

NA: Helped in study design, helped results interpretation and editorial help for manuscript.

NIB: Conceived the idea with HE, supervised the work, performed statistical analysis and finally approved the manuscript. 